images in clinical medicine

\title{
Acrospiroma of the left temporal region
}

\author{
Boris Jančar
}

Department of Radiation Oncology, Institute of Oncology Ljubljana, Ljubljana, Slovenia

An eighty-year-old patient was operated on for the tumour in the left temporal region. Surgery was performed at the University Department of Plastic Surgery and Burns of the University Medical Centre Ljubljana in December 2006. Before surgery, the tumour measured $6 \times 4 \mathrm{~cm}$. Histological examination of the excised tumour tissue confirmed acrospiroma (porocarcinoma).

The fine needle biopsy performed in April 2007 confirmed local recurrence of the disease (Figure 1).

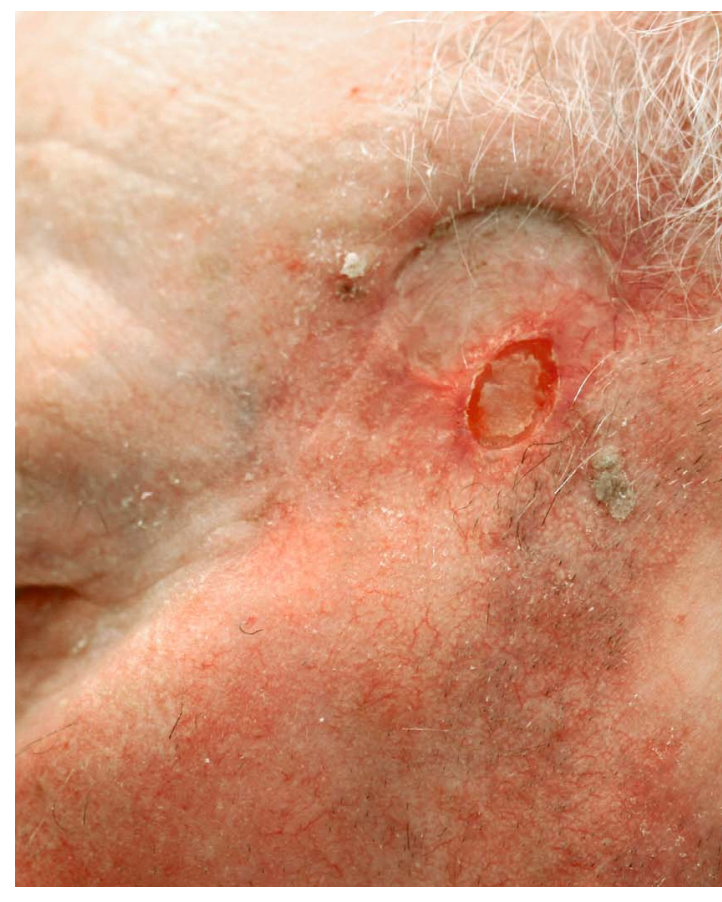

Received 28 November 2008 Accepted 14 January 2009

Correspondence to: Prim. Boris Jančar, MD, MSc, Department of Radiation Oncology, Institute of Oncology Ljubljana, Zaloška 2, Ljubljana, Slovenia; Phone; + 38615879 295; Fax: + 38615879 295; E-mail: bojancar@onko-i.si

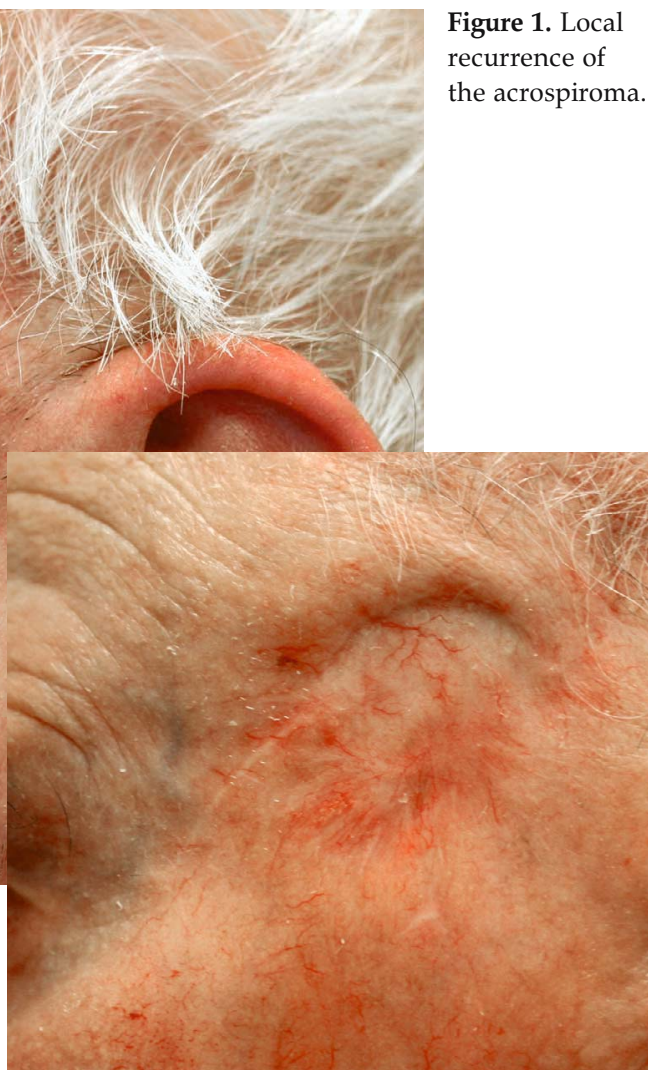

Figure 2. The tumour completely regressed after radiotherapy. 


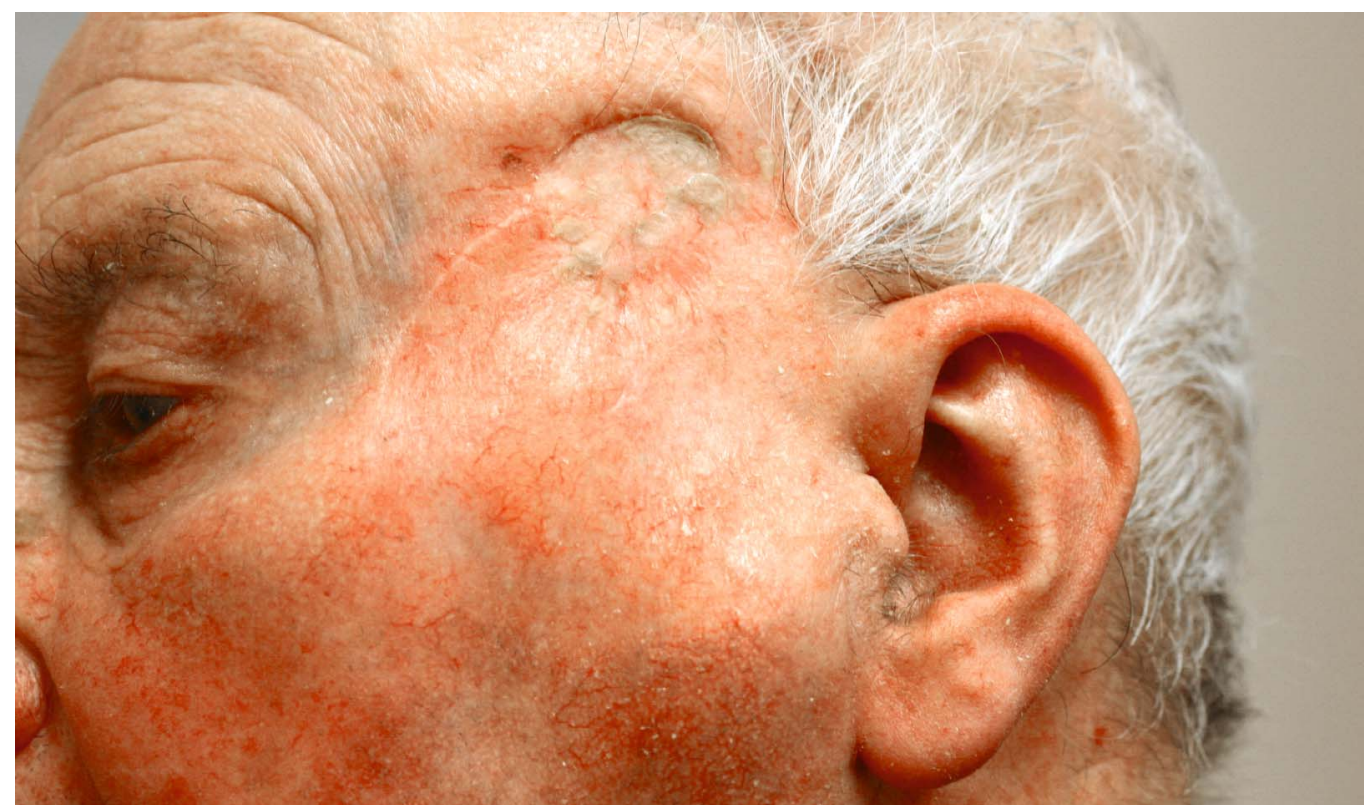

Figure 3. Metastasis in the parotid gland.

At that time, US examination of the neck did not detect any metastases. The skin lobe covering the section of the excised tumour and of the recurrence was irradiated by orthovoltage machine with a dose equivalent of $70 \mathrm{~Gy}$. The tumour completely regressed (Figure 2).

The fine needle biopsy performed in September 2007 detected a metastasis in the parotid gland (Figure 3). The patient was treated by telecobalt and electrons with a total dose equivalentof $70 \mathrm{~Gy}$.

Nine months after the completed radiotherapy, the patient's status was no evidence of disease (NED.), locally and regionally (Figure 4). At the last follow-up control 10 months after the completed radiotherapy, the patient again presented with NED.

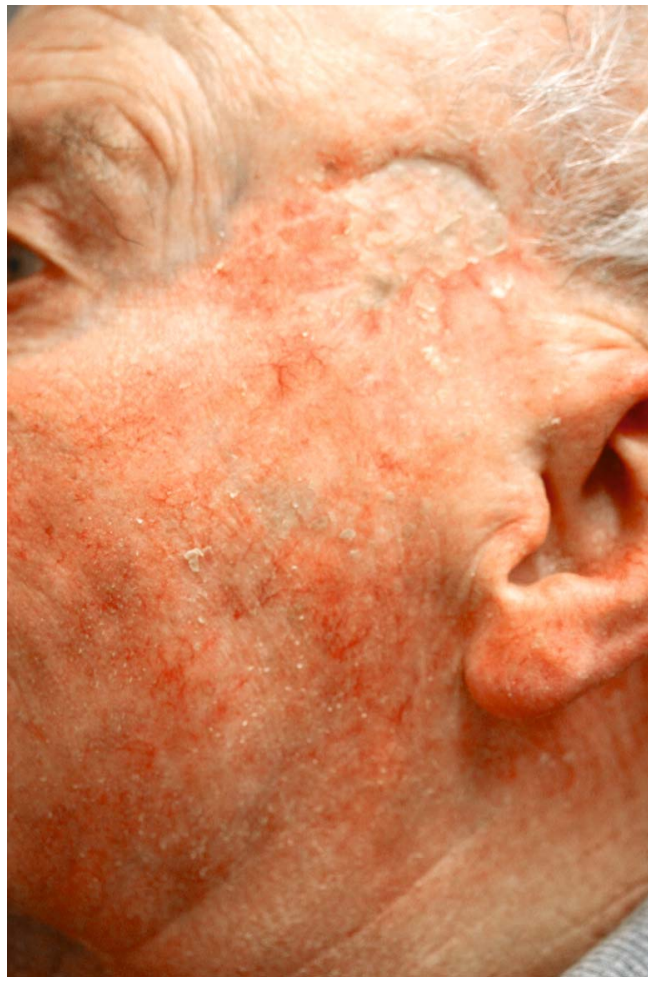

Figure 4. Nine months after the completed radiotherapy there was no evidence of disease. 